\title{
Emotion and attention: event-related brain potential studies
}

\author{
Harald T. Schupp ${ }^{1, *}$, Tobias Flaisch ${ }^{1}$, Jessica Stockburger ${ }^{1}$ and Markus Junghöfer ${ }^{2}$ \\ ${ }^{1}$ Department of Psychology, University of Konstanz, Konstanz, Germany \\ ${ }^{2}$ Institute for Biomagnetism and Biosignalanalysis, Münster University Hospital, Münster, Germany
}

\begin{abstract}
Emotional pictures guide selective visual attention. A series of event-related brain potential (ERP) studies is reviewed demonstrating the consistent and robust modulation of specific ERP components by emotional images. Specifically, pictures depicting natural pleasant and unpleasant scenes are associated with an increased early posterior negativity, late positive potential, and sustained positive slow wave compared with neutral contents. These modulations are considered to index different stages of stimulus processing including perceptual encoding, stimulus representation in working memory, and elaborate stimulus evaluation. Furthermore, the review includes a discussion of studies exploring the interaction of motivated attention with passive and active forms of attentional control. Recent research is reviewed exploring the selective processing of emotional cues as a function of stimulus novelty, emotional prime pictures, learned stimulus significance, and in the context of explicit attention tasks. It is concluded that ERP measures are useful to assess the emotion-attention interface at the level of distinct processing stages. Results are discussed within the context of two-stage models of stimulus perception brought out by studies of attention, orienting, and learning.
\end{abstract}

Keywords: emotion; attention; EEG; ERP; EPN; LPP

Humans live in an environment presenting a seemingly endless stream of stimuli. Only a subset of the available information is consciously recognized, becomes the focus of sustained attention, and is subjected to controlled and elaborated processing. Mechanisms of selective attention assure the prioritized processing of some objects, events, or locations and multiple avenues to command attention are indicated by distinguishing among active and passive forms of attentional control ${ }^{1}$ (Öhman et al.,

\footnotetext{
*Corresponding author. Tel.: + 497531 882504; Fax: + 49 7531 882971; E mail: Harald.Schupp@uni konstanz.de

${ }^{1}$ Similar to the distinction between active and passive atten tion, other classification schemata distinguish between auto matic vs. controlled, bottom up vs. top down, reflexive vs. instructed, implicit vs. explicit attention.
}

2000b). In passive attention, the power to capture attention derives from simple qualities of the stimulus such as intensity, suddenness of onset, or novelty. In active attention, priority processing reflects the intentional effort to look for selected stimuli based on instructions, self-generated intentions, or associative learning. In addition, certain kinds of stimuli trigger selective attention due to their biological meaning. Organisms respond to environmental cues according to their emotional/motivational significance (Lang et al., 1997; Öhman et al., 2000b). The attention capture of emotionally relevant stimuli has been dubbed 'motivated attention' referring to a natural state of selective attention, " ... similar to that occurring in an animal as it forages in a field, encounters others, pursues prey or sexual partners, and tries 
or void predators and comparable dangers" (Lang et al., 1997, p. 97). An evolutionary perspective suggests that this form of attentional control is highly adaptive for survival giving primacy in terms of attentional selection and response - to appetitively and aversively relevant events (Lang et al., 1997).

One aim of the present review is to present theory and data regarding the emotional guidance of selective attention in distinct processing stages. The review will discuss the effects of motivated attention from the perspective of the biphasic approach to emotion. Furthermore, we predominantly consider empirical evidence derived by event-related brain potential studies (ERPs). ${ }^{2}$ ERP measures have the unique advantage of high temporal resolution, and it will be concluded that they provide a useful tool to study the emotional guidance of attention at the level of distinct processing stages. A second aim of the present review is to extend this perspective to recent approaches examining the emotion-attention interface. Specifically, recent research is considered examining effects of motivated attention in relation to active and passive attention and learning. In the final section, the ERP indices of selective attentional orienting to emotional cues are discussed from the perspective of two-stage models of stimulus perception advanced in research of attention, orienting, and learning.

\section{A biphasic view of emotion}

Although emotional expressions, bodily changes, and reported feelings vary idiosyncratically according to dispositional and situational factors, many theorists claim that the emotional or affect system retains a much simpler biphasic organization of two distinct motivational subsystems (Schneirla, 1959; Konorski, 1967; Dickinson and Dearing, 1979; Lang et al., 1990, 1997; Lang, 1995; Cacioppo et al., 1999; Dickinson and Balleine, 2002). The self-preservative appetitive

\footnotetext{
${ }^{2}$ Discussion of the interaction of emotion and attention based on behavioral, autonomic, reflex, somatic, and neuroimaging measures are provided in recent reviews (Lang et al., 1997; Mogg and Bradley, 1999; Ohman et al., 2000a; Pessoa et al., 2002a; Compton, 2003; Vuilleumier, 2005).
}

system determines foraging, ingestion, copulation, and nurture of progeny, and is accompanied by affectively pleasant states. The protective defensive system coordinates withdrawal from and defense against nociceptive agents, and is associated with the experience of unpleasant affects. The view that emotion is in part organized by underlying motivational factors is supported by research utilizing verbal reports, which consistently demonstrates the primacy of the valence dimension. Furthermore, both motivational subsystems can vary in terms of engagement or activation reflecting the arousal level which is reliably observed as second dimension in studies of natural language and verbal reports (Lang et al., 1990, 1997).

Accordingly, emotions can be functionally considered as action dispositions preparing the organism for either avoidance or approach-related actions, interrupting ongoing behavior and mental processes (Frijda, 1986; Lang et al., 1997). Consistent with this view, a large number of studies demonstrated reliable modulations in autonomic, somatic, and reflex response measures while participants viewed pleasant, neutral, and unpleasant pictures (Bradley, 2000; Hamm et al., 2003). Presumably, emotional modulations are not limited to the behavioral output channels. They should also be evident during the preceding perceptual and evaluative processing of emotional cues. Specifically, efficient preparation and organization of appropriate behavioral responses require a rapid extraction of critical information from the environment. In this respect, emotional cues direct attentional resources (Öhman et al., 2000a). Furthermore, motivated attention reflects our evolutionary heritage and is therefore most apparent for stimuli with high evolutionary significance, that is, prototypical stimuli related to threat and survival strongly engaging basic motivational systems (Bradley et al., 2001).

\section{Emotion and attention: event-related brain potentials}

ERP measures provide a unique window into the brain's processing of emotional cues assisting in detailing information processing at the level of 
distinct stages. Already, the operation of selective processing triggered by reflexive or explicit attention has been greatly facilitated by the use of ERP measures. Specifically, an array of experimental tasks including the attentional blink, refractory period, visual search, and spatial cuing paradigms revealed modulations of specific ERP components thought to reflect perceptual encoding, working memory, and motor preparation processes (Luck and Hillyard, 2000; Luck et al., 2000). Similar to the domains of explicit and reflexive attention, it is expected that ERPs provide valuable information regarding the emotional guidance of selective attention. Three issues are of particular interest: (1) Identifying distinct processing stages at which emotional cues are selectively processed. (2) Determining whether the differential processing of emotional cues already affects obligatory processing stages. (3) Comparing the ERP signature of motivated and explicit attentional control.

ERPs provide a voltage measurement of neural activity that can be recorded noninvasively from multiple scalp regions (Birbaumer et al., 1990). More specific, ERPs are considered to reflect summed postsynaptic potentials generated in the process of neural transmission and passively conducted through the brain and skull to the skin surface where they contribute to the electroencephalogram (EEG). Since ERPs are usually hidden in the larger background EEG activity, it is necessary to use multiple stimulus presentations and the calculation of stimulus-locked signal averaging to extract the ERP signal from the background EEG activity. Biophysical considerations suggest that large-amplitude ERP components reflect widespread, synchronous sources in cortical regions (Lutzenberger et al., 1987). Brain activity locked to the processing of a stimulus becomes apparent as positive and negative deflections in the ERP waveform. The amplitude and latency of specific ERP components provide information regarding the strength and time course of underlying neural processes. Furthermore, given appropriate spatial sampling (Tucker, 1993), the topography of ERP components can be used to estimate the neural generator sites by advanced analytic tools such as Current-Source-Density (CSD; Perrin, Bertrand and Pernier, 1987) or L2-Minimum-Norm-Estimate
(L2-MNE; Hamalainen and Ilmoniemi, 1994; Hauk et al., 2002).

In the experiments summarized here, pleasant, neutral, and unpleasant pictures from the International Affective Picture System (IAPS; Lang et al., 2005) were presented in a passive task context in which subjects were instructed to simply view the pictures. Some of the reviewed studies used a $6 \mathrm{~s}$ picture presentation time and extended intertrial intervals, enabling the simultaneous assessment of autonomic and somatic measures of affect processing (Cuthbert et al., 2000; Schupp et al., 2004a). Other studies utilized the timing parameters of the modified oddball paradigm developed by Cacioppo and colleagues (Cacioppo et al., 1993) with shorter presentation times (1.5 s) and faster presentation rates (Schupp et al., 2000a, 2003a, 2004b). In addition, more recent studies using the rapid serial visual presentation (RSVP) paradigm are described, in which the pictures were presented briefly $(333 \mathrm{~ms})$ and as a continuous stream (Junghöfer et al., 2001; Schupp et al., 2003b, 2006, submitted; Wieser et al., 2006;). Furthermore, while earlier studies used sparse sensor sampling, more recent research provided an improved spatial sampling by using 128 or 256 sensor recordings. Due to limitations in head coverage and the placements of sensors, reliable differentiation of emotional and neutral contents within the first $300 \mathrm{~ms}$ was brought out in comparatively recent research (Junghöfer et al., 2001; Schupp et al., 2003b). Finally, earlier research exploring emotion processing is acknowledged, complementing the data reported in this review (Johnston et al., 1986; Diedrich et al., 1997; Johnston and Oliver-Rodriguez, 1997; Palomba et al., 1997). Across studies, the differential processing of emotional compared to neutral pictures was consistently and reliably reflected by three ERP components, which are summarized in the following according to their temporal occurrence in the processing stream.

\section{Early posterior negativity}

The first ERP component reflecting the differential processing of emotional compared to neutral stimuli is the early posterior negativity (EPN). The temporal 
and spatial appearance of the early indicator of selective processing of emotional pictures is illustrated in Fig. 1 presenting data from research utilizing the RSVP paradigm (Junghöfer et al., 2001). A pronounced ERP difference for the processing of emotionally arousing and neutral pictures developed around $150 \mathrm{~ms}$ which was maximally pronounced around 250-300 ms. This differential ERP appeared as negative deflection over temporooccipital sensor sites and a corresponding polarity reversal over fronto-central regions. Despite differences in the overall topography, research presenting pictures discretely and with longer presentation times (1.5 $\mathrm{s}$ and $1.5 \mathrm{~s}$ intertrial interval) also demonstrated a more pronounced negative potential for emotional pictures in the same latency range over temporooccipital sensors (Schupp et al., 2003a, 2004c). Additional analyses served to test the prediction derived from the biphasic view of emotion that the differential processing of pleasant and unpleasant cues varies as a function of emotional arousal. Consistent with this notion, the EPN co-varied with the arousal level of the emotional pictures. Specifically, highly arousing picture contents of erotic scenes and mutilations elicited a more pronounced posterior negativity compared to less arousing categories of the same valence (Junghöfer et al., 2001; Schupp et al., 2004b).

Given that these studies used natural scenes varying widely in terms of physical characteristics, it is important to explore to what extent the EPN effect is related to systematic differences in physical characteristics of the stimulus materials. To examine the effects of color of the stimulus materials, Junghöfer and colleagues (2001) included a control condition presenting the same materials as grayscaled images. An almost identical affect modulated early posterior negativity was observed as for the corresponding color images showing that the early discrimination of emotional from neutral pictures did not depend on color. Additional
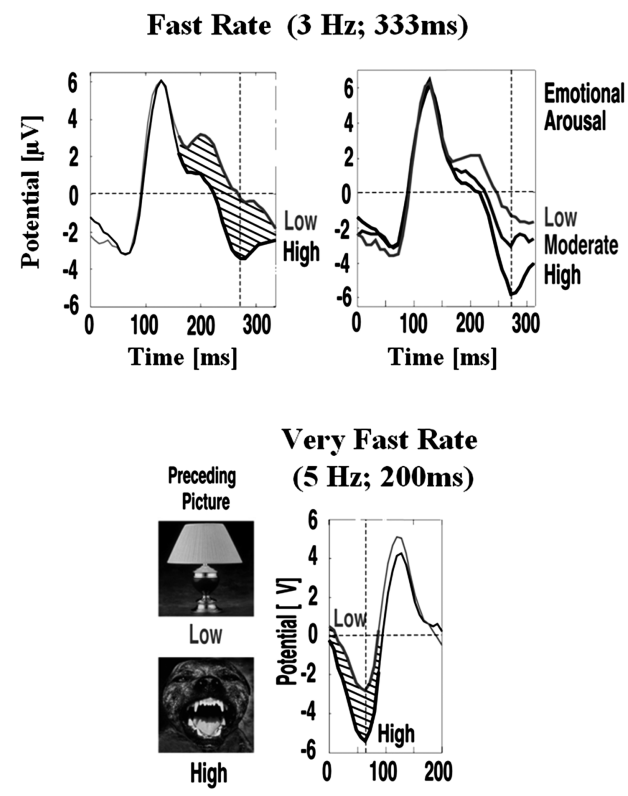
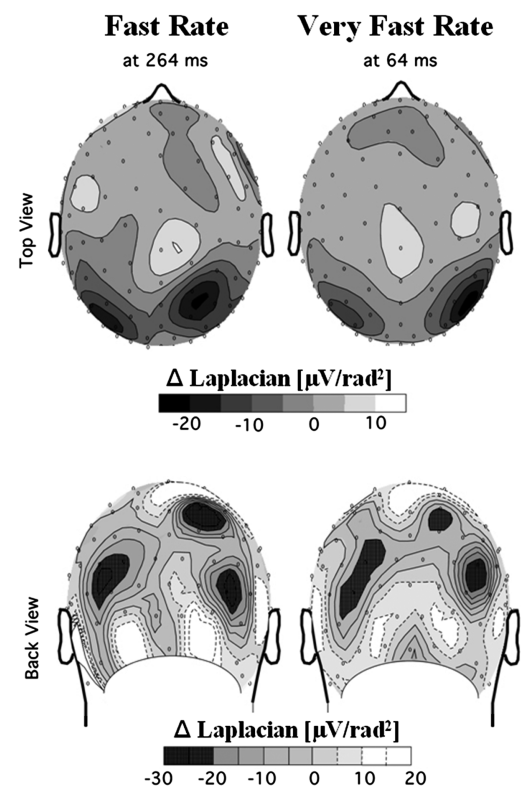

Fig. 1. Time course and topography of the early posterior negativity. Left side: Upper panel: Grand averaged ERP waveforms at a right occipital sensor while viewing high and low arousing (left side), and high, moderate, and low arousing pictures (right side), respectively. Pictures were presented at $3 \mathrm{~Hz}$. Lower panel: Grand averaged ERP waveforms at the same right occipital sensor while viewing high and low arousing pictures at $5 \mathrm{~Hz}$. The relative difference component peaking around $64 \mathrm{~ms}$ reflects the EPN of the preceding emotional picture. Right side: Top (upper panel) and back (lower panel) side views of the topographical distribution of the difference waves of (high low) arousing pictures for both the $3 \mathrm{~Hz}$ (left side) as well as the $5 \mathrm{~Hz}$ (right side) presentation rates. Scalp topography is shown in terms of current source density distribution estimating difference activities in bilateral occipito temporal and right hemispheric parietal cortex areas. 
control analyses determined that increased EPN amplitudes to emotional pictures were not secondary to differences in physical characteristics such as brightness, measures of perceptual complexity, or spatial frequency. However, a recent study provided a more systematic investigation of the EPN component as a function of picture content (objects vs. people), emotional arousal (low vs. high), and picture type (single foreground item vs. scattered scenes and multiple items; Löw et al., 2005). Each of these variables affected the EPN component suggesting that the EPN is not specifically reflecting emotional arousal but is presumably more generally related to perceptual variables determining selective attention. For instance, greater EPN amplitudes were obtained for people compared to objects, and pictures with a clear foreground object as opposed to more complex scenes. Interestingly, emotional effects were observed independent from picture type and content. However, in this study, high compared to low arousing pictures elicited augmented EPN amplitudes only for pictures depicting people. Accordingly, to determine the effects of emotional arousal, secondary explanations based on picture type and content need to be experimentally controlled by selecting appropriate picture materials (Schupp et al., $2004 a, b)$. From a theoretical perspective, it is unknown to what extent variables such as salient perceptual features, high evolutionary significance, and expert knowledge contribute to the emotional EPN modulation. Future research is needed to examine whether the EPN effect is limited to selected classes of emotional stimuli.

It might be informative to briefly outline the reasons that led to the decision to refer to this modulation as early posterior negativity associated with emotion processing (rather than reduced positivity). First, estimates of the neural generators by current source density (cf., Fig. 1; Junghöfer et al., 2001) and minimum norm analysis (cf., Fig. 3; Schupp et al., 2006) suggested that the difference in potential between emotional and neutral pictures has its sources over occipito-temporo-parietal sites. Second, with the notion of a stronger positive potential for neutral compared to emotional images, some readers might infer stronger neural activation for neutral materials. In fact, our accompanying functional magnetic resonance imaging (fMRI) studies indicate increased activation of the extended visual cortex while viewing emotional pictures in rapid serial visual presentations (Junghöfer et al., 2005, 2006). Third, paying explicit attention to specific stimulus features (such as color, orientation, or shape) and higher-order categories (e.g., animal vs. non-animal) is also reflected by a temporo-occipital negativity with a similar latency (Thorpe et al., 1996; Codispoti et al., in press).

In sum, a negative potential over temporo-occipital sensor sites, developing around $150 \mathrm{~ms}$ poststimulus and most pronounced around $200-300 \mathrm{~ms}$, reliably reflects the differential processing of emotional compared to neutral visual stimuli. These findings have been considered from the perspective of 'natural selective attention,' proposing that perceptual encoding is in part directed by underlying motivational systems of avoidance and approach. ${ }^{3}$

\section{Late positive potential}

As shown in Fig. 2, subsequent to the modulation during perceptual encoding, it is consistently observed that emotional (pleasant and unpleasant) pictures elicit increased late positive potentials (LPPs) over centro-parietal regions, most apparent around 400-600 ms poststimulus (also referred to as P3b; Palomba et al., 1997; Cuthbert et al., 2000; Schupp et al., 2000a, 2003a, 2004a, b; Keil et al., 2002; Amrhein et al., 2004). This LPP modulation appears sizable and can be observed in nearly each individual when calculating simple difference scores (emotional-neutral). In addition, the LPP is also specifically enhanced for pictures that are more emotionally intense (i.e., described by viewers as more arousing, and showing a heightened skin conductance response). Extending the valence by arousal interaction, a recent study examined the LPP amplitude associated with the processing of specific categories of human

\footnotetext{
${ }^{3}$ The present analyses might be extended to discrete states of emotion, considered to reflect a subordinate level of emotional organization. For instance, focusing on the fear system, we re cently obtained evidence that threatening faces are associated with increased EPN and LPP amplitudes compared to neutral and friendly faces (Schupp et al., 2004c).
} 
A

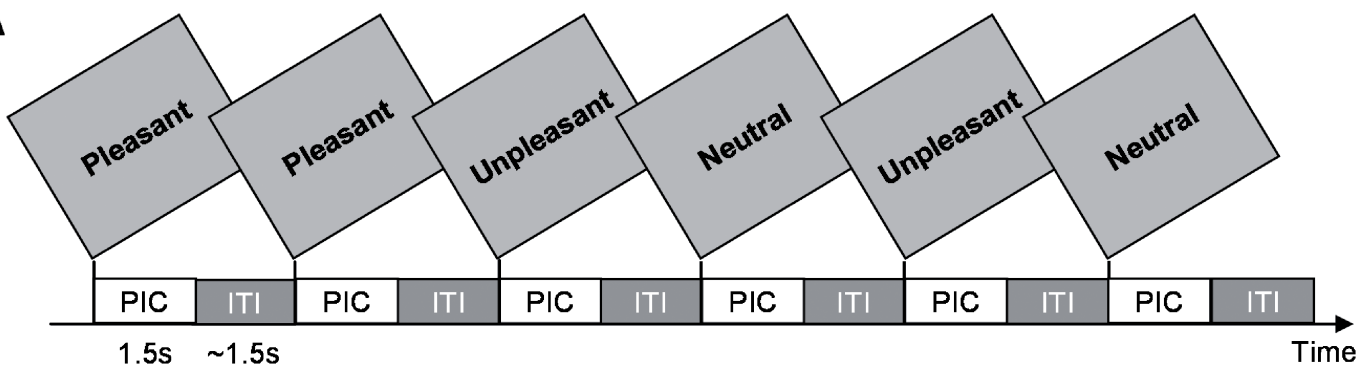

B

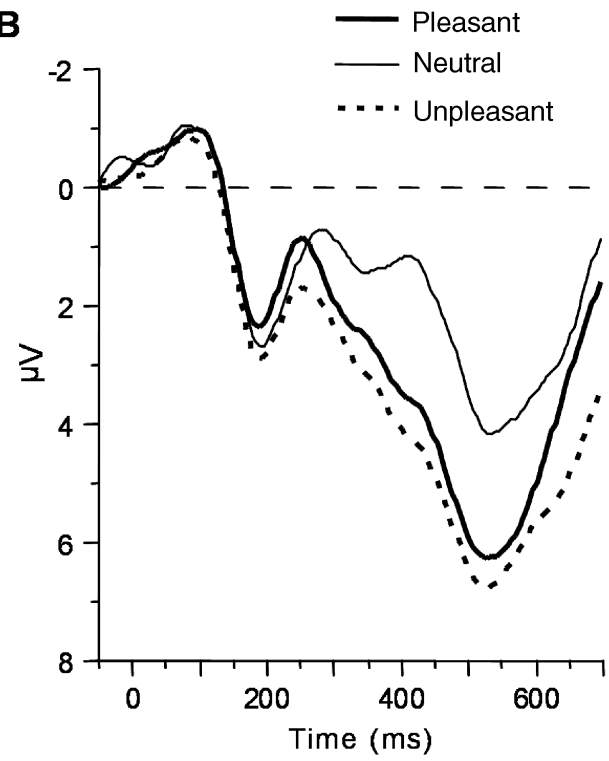

Difference: Emotional - Neutral

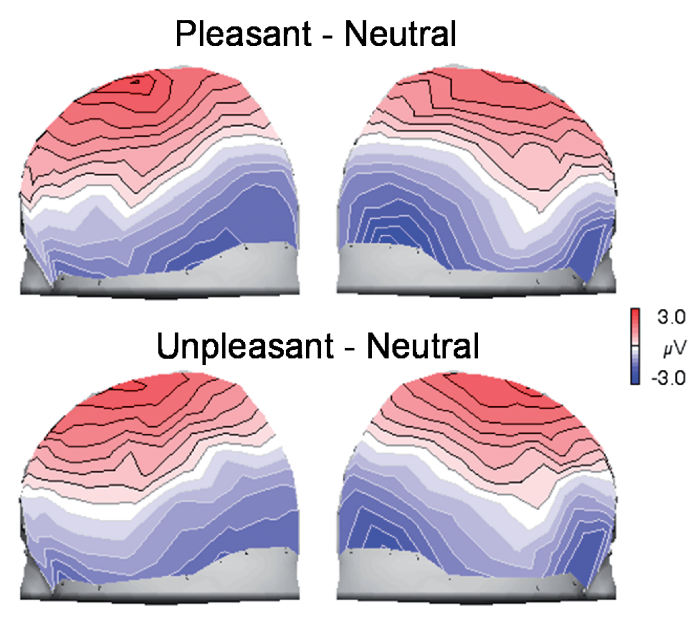

Fig. 2. Time course and topography of the late positive potential. (A) Illustration of the experimental paradigm used. Pictures are shown in blocks of six stimuli for $1.5 \mathrm{~s}$ each, separated by variable Intertrial Intervals (ITI) ( $\sim 1.5 \mathrm{~s})$. (B) Left side: Grand averaged ERP waveforms of a right parietal sensor while viewing pleasant, neutral, and unpleasant pictures. Right side: Difference scalp potential maps (emotional neutral) reveal the topography of the LPP modulation in the time interval of 400600 ms poststimulus. Illustrated is a left and right side view of the model head.

experience. Focusing on specific pleasant and unpleasant picture contents, it was found that picture contents of high evolutionary significance such as pictures of erotica and sexual contents and contents of threat and mutilations were associated with enlarged LPP amplitudes compared to picture categories of the same valence but less evolutionary significance (Schupp et al., 2004a).

In the cognitive domain, it is a hallmark finding that increased LPP amplitudes are associated with the meaning of task-relevant stimuli rather than just simple physical stimulus characteristics (Johnson, 1988; Picton, 1992). In addition, a close correspondence between instruction to attend to specified stimuli and the LPP amplitude associated with target detection has been reported. Moreover, dual-task studies revealed that the LPP amplitude to a primary counting task was reciprocally related to the LPP amplitude observed for a competing secondary task (Donchin et al., 1986). These findings suggest that the LPP is a sensitive measure of attention manipulations indicating the operation of a capacity-limited system. Functionally, the LPP amplitude has been considered to reflect the representation of stimuli in working memory (Donchin and Coles, 1988). Consistent with this view, research 
with the attentional blink paradigm indicates that the LPP might reflect a gateway to conscious recognition (Luck et al., 2000; Kranczioch et al., 2003). Considering these findings from cognitive research, it might be proposed that the increased LPP amplitude elicited by emotional cues reflects their intrinsic significance similar to the distinct representation in working memory of task-relevant stimuli.

An alternative interpretation might consider the LPP findings from the perspective of internal stimulus probability rather than emotional relevance. In fact, ample research documents that rare stimuli are associated with increased LPP amplitudes (Johnson, 1988). However, the LPP modulations discussed here appear to be unrelated to the probability of picture categories. When subjects had to spontaneously categorize the pictures on the basis of valence, the categories of pleasant, neutral and unpleasant contents were equally probable. Alternatively, assuming subjects saw the pictures as forming only two categories (emotional vs. neutral), the emotional stimuli were twice as frequent as neutral contents, as a consequence resulting in the opposite prediction as empirically observed: neutral pictures should have elicited larger LPP amplitudes compared to emotional categories. To resolve this issue more conclusively, the effect of stimulus probability and emotional context was explored in a follow-up study using the modified oddball paradigm. In this study, increased LPP amplitudes to emotional compared to neutral pictures were observed when these contents were interspersed in blocks of either neutral, pleasant, or unpleasant context stimuli (Schupp et al., 2000b). Thus, these data strongly suggest that emotional arousal is considerably more potent in determining LPP amplitude than local probability.

\section{Positive slow wave}

Research using longer picture presentation times revealed that the LPP is followed by an extended positive slow wave associated with the processing of emotional cues throughout the $6 \mathrm{~s}$ picture-viewing period (Cuthbert et al., 1995, 2000). In the cognitive domain, positive slow waves have been found to be sensitive to manipulations requiring sustained perceptual operations and memory processes (Ruchkin et al., 1988; Ritter and Ruchkin, 1992). Accordingly, it was suggested that the positive slow wave reflects sustained attention to visual emotional stimuli. This hypothesis is supported by research using a secondary acoustic probe presented during picture viewing. In these experiments, the P3 component of the probe ERP is reliably smaller when viewing pleasant or unpleasant, compared to neutral pictures (Schupp et al., 1997, 2004a; Cuthbert et al., 1998). This result parallels findings from experiments on instructed attention. When participants are told to attend to one stimulus and ignore others (Johnson, 1988), a smaller P3 response to a secondary probe is consistently found during the attended stimulus. This result is held to reflect reduced availability of attentional resources for the probe, assuming that the resource pool is limited and there is high allocation to the primary stimulus (Donchin et al., 1986).

\section{Summary}

Summarizing these findings, a number of observations merit reemphasis:

(1) The emotional guidance of selective attention is reflected by three distinct ERP components associated with different stages of stimulus processing including perceptual encoding, stimulus representation in working memory, and elaborate stimulus evaluation.

(2) ERP modulations induced by emotional cues were reliable and consistently observed early in the processing stream $(<300 \mathrm{~ms})$.

(3) Indices of selective attention observed for motivated and instructed attention appear strikingly similar.

\section{Exploring the emotion-attention interface}

Building upon these findings, recent research was directed towards understanding effects of motivated attention in interaction with active and passive forms of attentional control. One goal of these studies was to determine the boundary conditions of the differential emotion processing. Thus, interference of the selective emotion processing was 
determined as a function of stimulus novelty, competition by primary cognitive tasks, and the processing of emotional prime pictures. Another interest was to determine effects of cooperation, that is, when selective attention is devoted to emotional stimuli. Furthermore, learning and experience may shape attentional orienting as investigated in selected subject populations (e.g., simple phobia, substance abuse).

\section{Stimulus novelty and emotional perception}

In passive attention, stimuli may capture attentional resources simply because they are novel. In the studies described above, no extensive stimulus repetitions were implemented. Therefore, it remains to be determined to what extent the observed emotional attention capture depends on stimulus novelty. Widely studied in the context of the orienting response, the repeated presentation of sensory stimuli usually prompts habituation, that is, decrement across several response systems (reviewed in Öhman et al., 2000b). Recent studies have demonstrated the importance of stimulus novelty for differential emotion processing measuring various motor output responses. Specifically, studying habituation in processing of emotional stimuli, skin conductance responses, heart rate, and corrugator muscle activity habituated rather quickly. In contrast, the startle reflex magnitude continued to be augmented for unpleasant compared to pleasant picture contents across repeated stimulus presentations (Bradley et al., 1993). Thus, habituation effects differ among measures of motor output and response preparation, and a series of recent studies extended the database to ERP measures of stimulus perception and evaluation. Given the attention capture by emotional cues may reflect a rather automatic phenomenon (Öhman et al., 2000a), stimulus novelty might be less critical during perceptual processing and stimulus representation in working memory.

To separate emotional meaning and stimulus novelty, the processing of erotica, neutral contents, and mutilations was examined across 90 picture repetitions (Schupp et al., 2006). Replicating previous results, emotional stimuli were associated with increased EPN amplitudes compared to neutral pictures. Interestingly, differential emotion processing did not vary as a function of stimulus repetition and was similarly expressed across blocks of picture presentation (cf., Fig. 3). One might assume that presenting the pictures as continuous stream may be particularly effective in triggering attentional orienting to each stimulus, in effect preventing differential emotion processing from habituating. To pursue this possibility, a follow-up study presented the pictures for $120 \mathrm{~ms}$, preceding a blank period of $880 \mathrm{~ms}$. In this instance, three pictures displaying erotic, neutral, or mutilation scenes were repeated 700 times (Schupp et al., unpublished data). Again, the erotic and mutilation pictures elicited an increased EPN compared to the neutral scene, revealing no habituation as a function of excessive stimulus repetition. This issue was examined in yet another study focusing on the habituation of differential emotion processing indexed by the LPP amplitude (Codispoti et al., 2006). Three pictures displaying pleasant, neutral, or unpleasant scenes were repeated 60 times. Furthermore, to obtain autonomic and somatic indices of emotion processing, pictures were presented at slow rates. Results revealed augmented LPP amplitudes to pleasant and unpleasant compared to neutral pictures, which was maintained across repeated presentations of the stimuli. These results concur with findings in the cognitive domain observing pronounced LPP amplitudes in visual search tasks promoting automatic target detection (Hoffman et al., 1983). These studies suggest that stimulus novelty is not critical to observe differential processing of emotional compared with neutral stimuli reflected by EPN and LPP component.

It has been suggested that perceptual processing in the cortex is regulated by subcortical structures involved in appetitive or defensive responding (Derryberry and Tucker, 1991; Davis and Whalen, 2001; Junghöfer et al., 2005; Sabatinelli et al., 2005). The present findings appear inconsistent with this hypothesis, considering that several studies observed relatively rapid habituation effects in the amygdala to emotional facial expressions. In addition, habituation effects were also demonstrated for the cingulate cortex, the hippocampus, and the dorsolateral prefrontal cortex (Breiter 
a

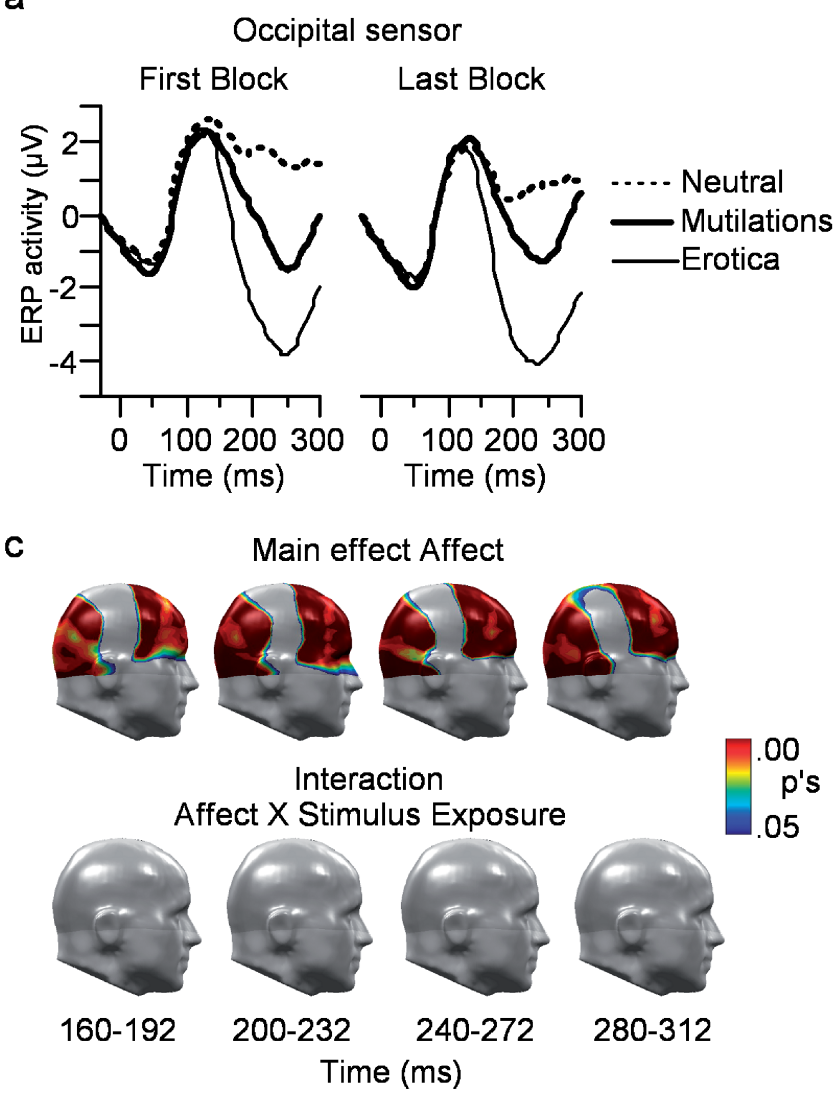

b

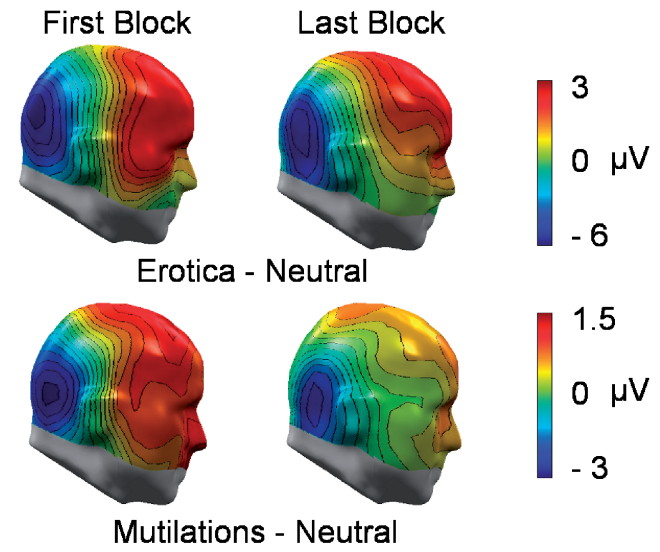

d
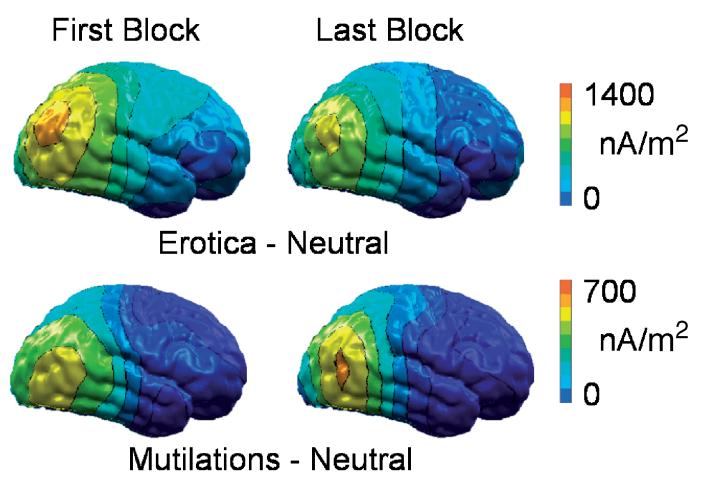

Fig. 3. Effects of emotion and stimulus repetition.(a) Grand averaged ERP waveforms for a selected right occipital sensor as a function of affect and first and last block of picture viewing. (b) Difference scalp potential maps (emotional neutral) for the first and last block of picture presentation separately. (c) Illustration of the statistical effects observed in repeated measure ANOVAs calculated for each sensor and mean time interval. (d) Calculation of the L2 MNE for the scalp potential difference (emotional neutral) separately for first and last block of picture presentation. All maps display a right side view.

et al., 1996; Wright et al., 2001; Phan et al., 2003). However, a number of critical issues and findings need to be taken into account. First, as observed in a classical conditioning fMRI study, habituation may vary for the various anatomical subregions of the amygdala serving distinct functions (Morris et al., 2001). Second, a recent study observed that patients with amygdala lesions did not show enhanced activity to fearful faces in the fusiform and occipital gyri, which was indeed found for a group of healthy controls (Vuilleumier et al., 2004). Finally, sizeable BOLD activations in the amygdala have been observed for highly arousing emotional materials (Junghöfer et al., 2005; Sabatinelli et al., 2005), and it remains to be determined in future studies whether the amygdala also reveals rapid habituation to these emotionally evocative stimuli. Thus, more research is needed to evaluate the hypothesis that the preferential processing of emotional images in the extended visual cortex is secondary to the appraisal of affective significance in the amygdala. Alternatively, as discussed in associative learning, limbic structures such as the amygdala might modulate the associative strength of cortical stimulus representations of emotionally significant materials (Büchel and Dolan, 2000).

Taken together, habituation studies have shed light on the role of stimulus novelty in emotion picture processing. Across several studies, we 
observed that the differential processing of emotional compared to neutral stimuli indexed by the EPN and LPP components did not depend on stimulus novelty and were maintained across numerous stimulus repetitions. These findings suggest that detecting emotionally significant stimuli in the environment might be an obligatory task of the organism, apparently not habituating as a function of passive exposure.

\section{Emotion processing in the context of primary attention tasks}

Recent studies approached the interaction of emotion and attention from the perspective of competition by concurrently presenting emotional stimuli and nonemotional task-relevant stimuli (Vuilleumier and Schwartz, 2001; Pessoa et al., 2002b; Anderson et al., 2003). For instance, relying on a primary spatial attention task, Vuilleumier and Schwartz (2001) demonstrated the selective activation of the amygdala and fusiform gyrus to fearful faces independent of whether the faces were presented at attended or unattended spatial locations. In another study, Pessoa and colleagues (2002b) observed that selective emotion processing depended on the availability of attentional resources. In their critical condition, subjects had to discriminate the orientation of eccentrically presented bars while maintaining fixation on centrally presented emotional or neutral faces. Contrasting with control conditions without additional task load, emotional faces did not elicit increased activation, neither in visual processing areas, nor in the amygdala. These data were interpreted from the perspective of the biased competition model of visual attention, assuming that emotional and task-relevant representations competed for processing resources in the visual cortex (Desimone and Duncan, 1995; Pessoa et al., 2002a). Complementary evidence was provided by recent ERP research. For instance, Pourtois and colleagues (2004) observed that task-relevant bar stimuli cued by fearful rather than neutral faces were associated with increased P1 components over lateral occipital leads. In addition, Holmes and Colleagues (2003) observed a reduced N1 peak over frontal sites to fearful as compared to neutral faces specifically when the faces were presented at attended locations while absent when presented at nonattended locations. Taken together, these data suggest the interference of selective emotion processing when attentional resources are directed to locations of explicitly task-relevant stimuli.

Pursuing the interaction of emotion and attention, Schupp and colleagues (2003b) studied the hypothesis of obligatory selective emotional processing while subjects performed a feature-based explicit attention task. Towards this end, task-irrelevant pleasant, neutral, and unpleasant images were presented while subjects had to detect target checkerboard images interspersed in the picture sequence. In order to increase perceptual load, stimuli were presented as a rapid continuous stream with individual presentation times of $333 \mathrm{~ms}$. The findings revealed increased EPN amplitudes to pleasant and unpleasant stimuli, particularly pronounced for stimuli of high evolutionary significance. Additionally, behavioral and electrophysiological responses to the task stimuli showed successful top-down attentional control to nonemotional stimuli. This research illustrates the selective processing of emotional cues while these stimuli were irrelevant to the primary cognitive task.

A stronger test for the hypothesis of the automatic nature of selective emotion processing was implemented by a study presenting emotional pictures and task-relevant information concurrently. As shown in Fig. 4(A), target and distracter stimuli were created by grids of horizontal and vertical lines, which were presented overlaying the IAPS pictures. To systematically vary the task load, the proportion of stimuli presenting the IAPS pictures with or without the overlaid task-relevant grid-pattern, respectively, was changed in four experimental conditions. Specifically, in separate blocks, task-relevant stimuli occurred with $10 \%$, $50 \%$, or $100 \%$ probability, respectively, while an additional control condition presented no task stimuli in order to replicate previous findings. The order of the four experimental conditions was balanced across subjects. Results closely replicated previous findings for the control condition with pleasant and unpleasant pictures eliciting a pronounced EPN amplitude relative to neutral 
A

\section{$0 \%$ taskrelevant trials „watch pictures" \\ $100 \%$ taskrelevant trials „count pictures with vertical lines ${ }^{x}$}
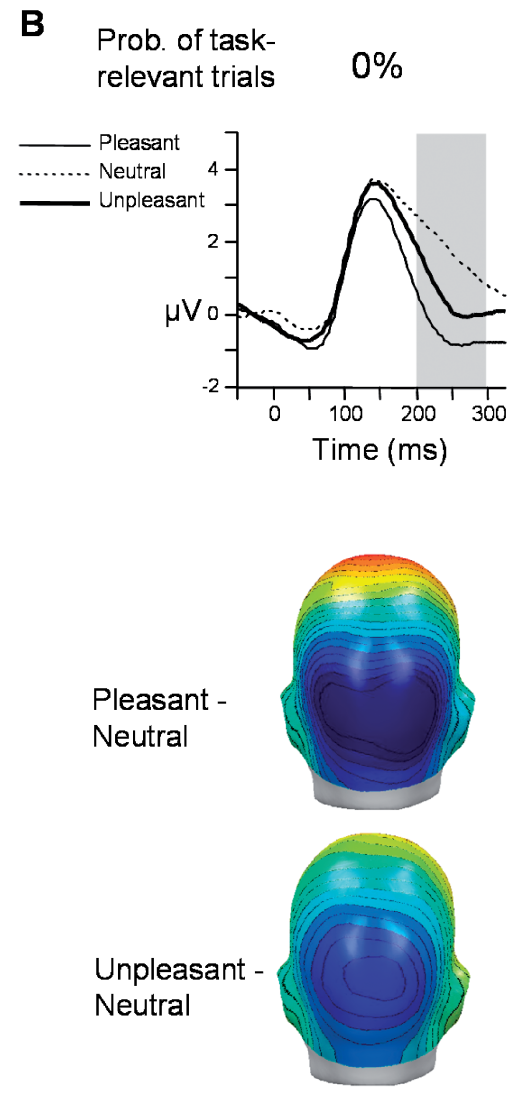
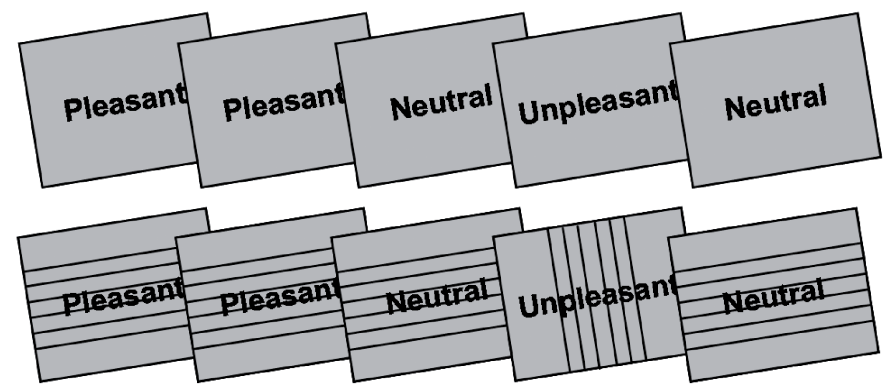

$$
10 \% \quad 50 \% \quad 100 \%
$$
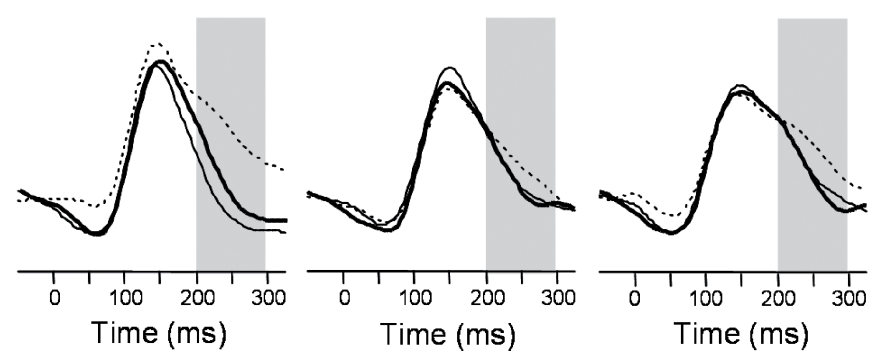

\section{Difference: Emotional - Neutral}
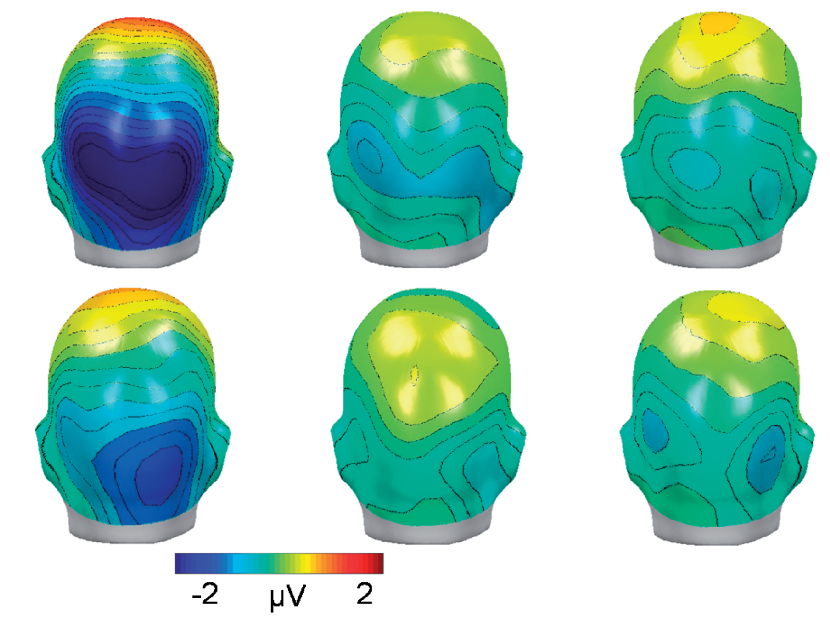

Fig. 4. Interaction of emotion and explicit attention. (A) Illustration of the used RSVP paradigm in two of four conditions. Upper row: passive viewing condition with IAPS pictures. Lower row: task condition with overlaid grid patterns in each trial. In this example, the fourth trial represents the rare target stimuli. (B) Upper panel: Grand averaged ERP waveforms of pleasant, neutral, and unpleasant pictures in the four experimental conditions for a right occipital sensor. Gray shaded area is the analyzed EPN time interval from $200300 \mathrm{~ms}$. Lower panel: Topographical difference maps for pleasant neutral and unpleasant neutral in the four conditions projected on the back view of a model head.

cues. Furthermore, occasionally interspersed task stimuli $(10 \%$ condition) did not interfere with the processing of emotional compared to neutral stimuli. Again, an active task set did not interfere with selective emotion processing of pictures not presenting task-related information (Schupp et al., 2003b). However, interference effects were pronounced in those conditions with higher task load. 
The differentiation between emotional and neutral stimuli was greatly attenuated during the $50 \%$ and $100 \%$ conditions (cf., Fig. 4). As expected by an interference account, ERP indices of selective attention to the task-related stimuli were obtained. Specifically, target compared to distracter stimuli revealed increased EPN and LPP amplitudes.

Taken together, consistent with the notion of capacity limitations during perceptual encoding, these data suggest that explicit attention to taskrelated stimuli interferes with selective processing of emotional 'background' information. Interestingly, a similar pattern of results was obtained when the visual oddball task was substituted by an auditory one (Schupp et al., unpublished data). The same ERP component, which was found to be insensitive to stimulus novelty, was modified by explicit attention control mechanisms suggesting that the stimulus-driven attention capture interacts with the goal-driven control of attention.

\section{Emotional perception as a function of prime stimuli}

Interference effects may not be limited to concurrently presented stimuli, but may extend in time. In the real world, stimuli often appear not in isolation but follow each other, raising the question to what extent the selective encoding of emotional pictures varies as a function of the emotion category of a preceding 'prime' picture. For instance, is the processing of an erotic scene facilitated when preceded by another pleasant image rather than a scene of threat? Considered from the perspective of motivated attention (Lang et al., 1997), processing resources are automatically captured and sustained by emotional cues (Cuthbert et al., 2000; Keil et al., 2002). Accordingly, one might expect that an emotional prime picture drawing heavily from limited processing resources is hampering the processing of subsequently presented stimuli. Thus, the motivated attention hypothesis assumes that target picture processing will vary as a function of processing resources devoted to both prime and target pictures. Specifically, emotional target pictures are associated with a larger EPN compared to neutral images, and, emotional prime pictures, themselves associated with an increased EPN, should reduce the posterior negativity of subsequent target pictures. While congruence in hedonic valence between a prime and a target picture has no special status in a motivated attention framework, such effects might be predicted from the perspective of affective priming. A typical finding in behavioral priming tasks is that target words are evaluated faster when preceded by a short-duration (e.g., $300 \mathrm{~ms}$ ) prime of the same hedonic valence (for reviews see Bargh, 1989; Klauer and Musch, 2003). Affective priming may reflect spreading activation (Ferguson and Bargh, 2003) and this perspective would predict an interaction of prime and target picture category due to the facilitated processing of target pictures preceded by prime pictures of the same valence category.

To examine this issue (Flaisch et al., submitted), subjects viewed a continuous stream of pleasant, neutral, and unpleasant pictures, presented for $335 \mathrm{~ms}$ each. In order to examine the effects of emotional primes on target picture processing, separate average waveforms were calculated for nine experimental cells (three emotional picture categories for the prime and target picture, respectively). As expected, emotional target pictures were associated with a larger early posterior negativity, compared to neutral ones. Moreover, it was found that the magnitude of the EPN for a target picture varied systematically as a function of the preceding prime (cf., Fig. 5). When a prime picture was emotional (and itself elicited an enhanced early posterior negativity), the EPN of the subsequent target picture was reduced. This effect of an emotional prime image was identical regardless of whether the target picture was pleasant, neutral, or unpleasant. Thus, the data revealed no evidence for affective priming in the perceptual domain. Rather, whether the hedonic valence of the prime was congruent or incongruent with the following target, occipital negativity of the target picture was decreased if the prime picture was affectively engaging.

The novel finding of this study is that current target processing is affected not only by the emotional content of the current image but also systematically varies with the emotional content of the preceding prime picture. These findings imply that the capture of processing resources extends in 
A)

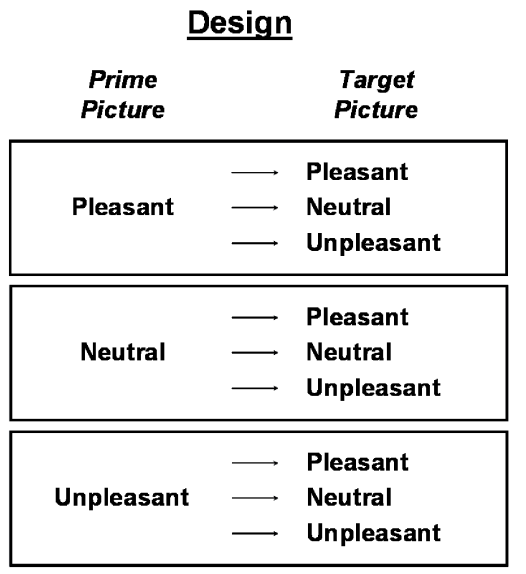

C)

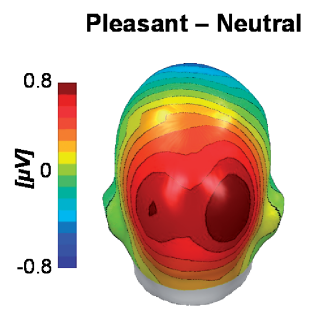

\section{Difference Maps}

Unpleasant - Neutral

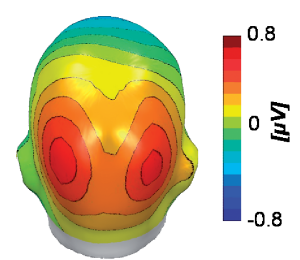

B)

Prime Effect on Target Processing

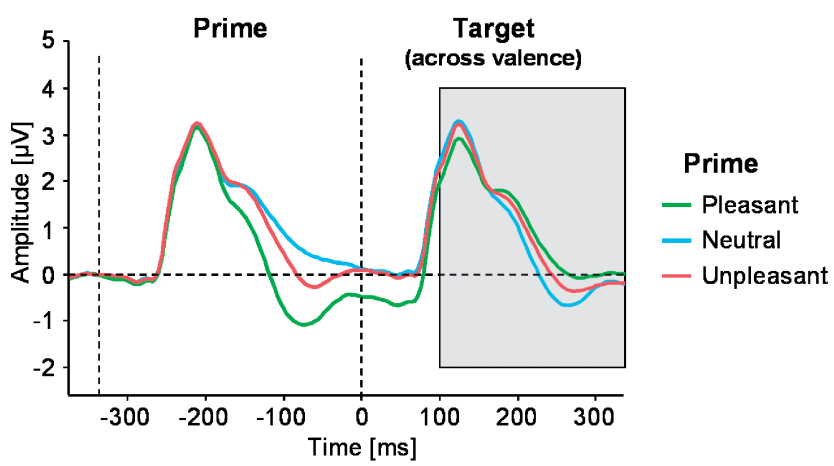

Fig. 5. Effects on target picture processing as function of preceding prime pictures. (A) Illustration of the prime target picture combinations examined in this study. (B) Upper panel: ERP waveforms for a representative right occipital sensor illustrating the main effects of prime (right part) and target (left part) valence. The prime effect is illustrated by reduced posterior negativities following emotional compared to neutral prime pictures averaged across pleasant, neutral, and unpleasant target pictures. Lower panel: Detailed illustration of the prime effect on target processing by presenting waveforms separately for pleasant, neutral, and unpleasant target pictures. (C) Scalp potential maps of the difference waves (pleasant neutral) and (unpleasant neutral) in the time interval of $248288 \mathrm{~ms}$ post target picture onset reveal the topographical distributions of the modulation of target picture processing as a function of prime valence.

time and interferes with successively presented stimulus materials. These data are consistent with the notion that successively presented pictures are characterized by a distinct neural representation, which may compete for a limited pool of processing resources (Kastner and Ungerleider, 2000; Keysers and Perrett, 2002; Potter et al., 2002). However, rather than being limited to concurrent stimulus processing, the present results suggest that processing resources allocated to target pictures systematically vary with the amount of processing resources captured by preceding emotional prime stimuli. Furthermore, previous studies assessed competition effects mainly by introducing an explicit attention task. In contrast, the pattern of results was observed here in the absence of any active task instruction, presumed to reflect the implicit capture of attention by emotional cues (Öhman et al., 2000a).

\section{Paying explicit attention to emotions}

Competition designs explore the boundary conditions of the differential processing of emotional cues. In real life, however, both forces assuring attentional orienting, namely motivated and explicit attention, often cooperate. This raises the question whether paying attention to emotional rather than neutral contents is even more effective in drawing attentional resources. Thus, the 
interplay of attention and emotion was examined under conditions when these two forces pull in the same direction (Schupp et al., submitted).

In this study, subjects viewed a rapid and continuous stream of pictures displaying erotic, neutral, and mutilation contents while the EEG was recorded with a 128 dense sensor array. In separate runs, each of the three picture categories served as target category in a counting task. Target stimuli were defined according to their emotional valence, and therefore, both avenues to induce selective attention were assessed within the same experimental context. It is worth noting that detecting emotional and neutral target stimuli elicited increased occipital negativity and late positive potentials with similar topography and latency as in previous studies requiring subjects to detect animal targets (Thorpe et al., 1996; Delorme et al., 2004; Codispoti et al., in press). As expected, selective emotional processing closely replicated previous findings (Cuthbert et al., 2000; Junghöfer et al., 2001; Keil et al., 2002; Schupp et al., 2003b, 2004b), and was associated with a similar cortical signature as instructed attention. Establishing these cortical indices of selective attention due to implicit emotional and explicit task-defined significance provides the foundation to meaningfully interpret the observed interplay of attention and emotion. Interestingly, overadditive effects of paying attention to emotional rather than neutral contents were only observed at later stages of processing indexed by the LPP (c.f., Fig. 6). This effect appeared sizable, the amplitude of the late positive potential almost doubled when attending to emotional rather than neutral contents. In contrast, effects of emotion and task relevance were independent from each other during earlier perceptual processes indexed by the EPN. Thus, ERP indices tracking the unfolding of stimulus processing revealed a shift in the interplay of directed attention and emotional stimulus significance. Attending to emotional cues appeared particularly efficient to boost the LPP component. This may point to a capacity-limited serial processing system possibly involved with short-term memory representations needed for focused attention and conscious recognition.

The shift in the interplay of target and emotion relevance from independent to overadditive effects is presumably secondary to changes in neural structures controlling the expression of selective attention. The structures believed to be involved in selective visual processing of target and emotional task relevance are heavily interconnected, providing possible anatomical pathways to implement boosted processing of emotional targets. For instance, heavy interconnections are described for the dorsolateral prefrontal cortex, a key structure in the frontoparietal network organizing explicit attention effects, and the ventromedial prefrontal cortex, part of the paralimbic and limbic network implicated in emotional stimulus evaluation (Barbas, 1995; Davis and Whalen, 2001; Ghashghaei and Barbas, 2002; Bar, 2003). Consistent with anatomical data, recent fMRI studies revealed the interplay among these structures when attention was directed to the location of emotionally relevant stimuli or when target detection was compared to the processing of emotional distracters (Armony and Dolan, 2002; Yamasaki et al., 2002). However, considering the interplay of attention and emotion from the perspective of specific subprocesses, a recent theory is relevant linking late positive potentials to the activity in a specific neuromodulatory system, namely the ascending locus coeruleus-norepinephrine (LC-NE) system which is presumed to increase the gain of cortical representations (Nieuwenhuis et al., 2005). From this perspective, the overadditive effects of paying attention to emotional targets might be secondary to the engagement of the neuromodulatory LC-NE system, a hypothesis awaiting more direct evidence by future research.

Taken together, there is first evidence that obligatory emotion processing interacts with explicit attention processes. However, providing support for the claim of an interaction between attention and emotion at the level of specific subprocesses, the relationship between emotion and attention varied across processing stages. Explicit attention effects and emotional significance operated additively during early perceptual stimulus categorization while synergistic effects of implicit emotion and explicit attention effects were observed during the stage of higher-order conceptual stimulus representation in working memory. 
A
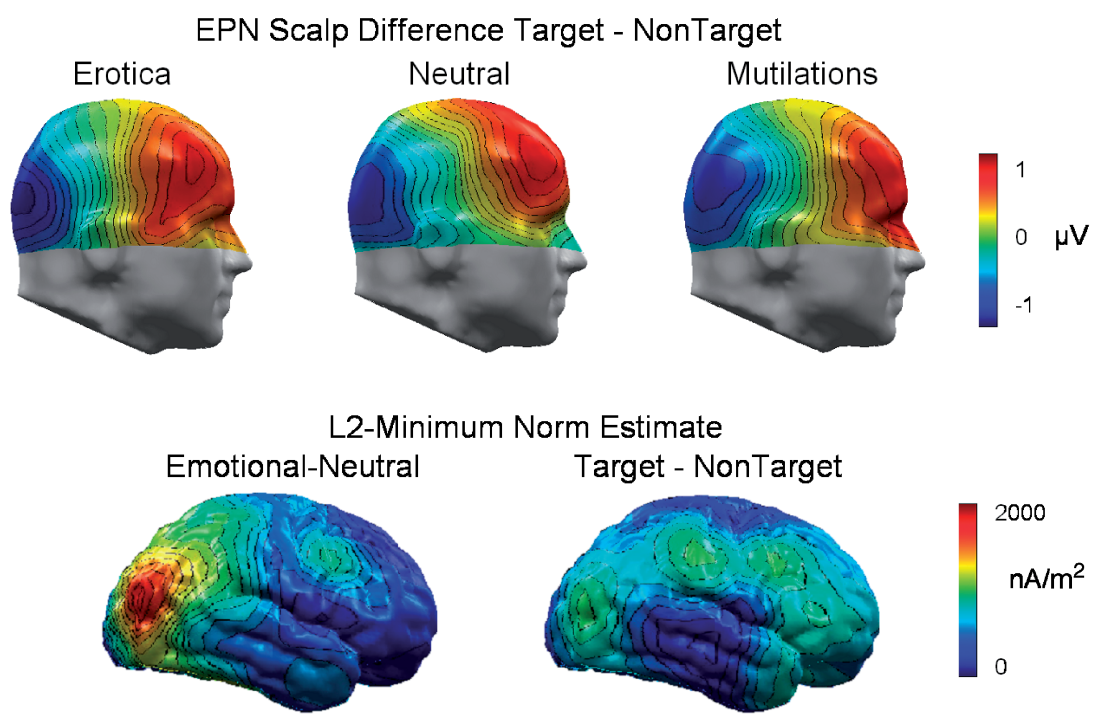

B

LPP Scalp Difference Target - NonTarget
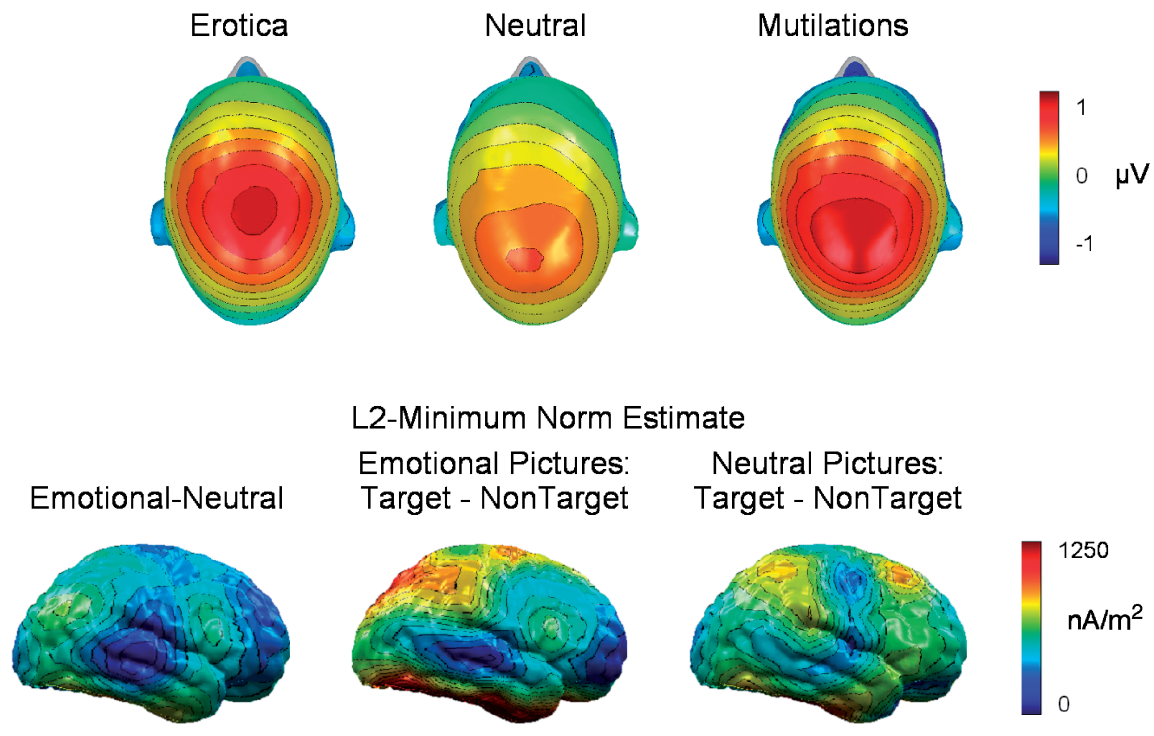

Fig. 6. Effects of cooperation between emotional and explicit attention. (A) Upper panel: Scalp difference maps (target non target stimuli) for erotic, neutral, and mutilation images in the EPN time window. Lower panel: Calculation of the L2 MNE for the scalp potential difference illustrating emotion and explicit attention effects. (B) Upper panel: Scalp difference maps (target non target stimuli) for erotic, neutral, and mutilation images in the LPP time window. Lower panel: Calculation of the L2 MNE for the scalp potential difference illustrating the interaction of emotion and attention. All maps display a right side view.

\section{Learned stimulus relevance and attentional orienting}

The perspective that emotional cues capture attentional resources provides a framework to investigate subject populations responding highly emotional to selected stimuli. Accordingly, the issue is raised how individual experience and learning shape the attentional orienting to these stimuli 
in distinct processing stages. Previous studies already provided evidence for a pronounced attention capture by fear-relevant stimuli in specific phobia. For instance, subjects with small animal phobia display a pronounced defensive reactivity to fear relevant stimuli, that is, augmented defensive startle magnitude, as well as heightened autonomic responsivity and increased activation in the amygdala and infero-temporal cortex (Hamm et al., 1997; Cuthbert et al., 2003; Sabatinelli et al., 2005). Building upon these findings, we recently used rapid serial visual presentations to explore whether fear-related pictures are associated with enhanced EPN amplitudes in snake or spider phobics. Consistent with this hypothesis, the EPN was largest for snake and spider pictures in snake and spider phobics, respectively. However, the effect appeared more robust in snake phobics (Schupp et al., unpublished data). Focusing on spider phobia, a follow-up study including a larger sample revealed only marginally increased EPN amplitudes to fear relevant materials in spider phobics compared to healthy controls. This study observed pronounced enlarged LPP and slow wave amplitudes for the processing of fear-relevant stimuli in phobics compared to control participants (Michalowski et al., 2005). Similar results have also been reported by Miltner and colleagues (2005). Yet another line of research examined this issue focusing on addiction and the processing of drug-associated cues such as heroin, alcohol, cocaine, and tobacco (Franken et al., 2004). Increased LPP and slow wave amplitudes have been observed in heroin-dependent compared to control individuals in drug-associated pictures depicting cocaine and heroin (Franken et al., 2003, 2004).

Taken together, evidence accumulates suggesting that ERP measures derived in research of emotion processing in healthy individuals might contribute to the understanding of clinically relevant issues. Previous research provides ample evidence that learning and experience triggers pronounced and fast physiological responses to clinically relevant stimuli (Globisch et al., 1999; Öhman et al., 2000b). Extending these data, disorder-related stimuli appear to trigger exaggerated responding in specific ERP components partitioning the attention capture in substages. However, current results appear not fully consistent and await more conclusive research. In particular, future studies using dense sensor ERP arrays may enable to provide a better assessment of the early selective stimulus processing. Also, examining clinically relevant stimuli as well as standard pleasant, neutral, and unpleasant materials in a range of disorder groups appears particularly informative. One promise of this endeavor is that ERP measurements may become a sensitive tool to evaluate effects of behavior therapy complementing fMRI and startle probe measurements (Vrana et al., 1992; Straube et al., 2005).

\section{Summary}

Experimental approaches to explore the emotion-attention interface further the understanding of the emotional capture of attentional resources in distinct processing stages. One issue is to determine to what extent the EPN component reflects an automatic phenomenon, that is, the unintentional, unconscious, and effortless processing of emotional cues. Suggestive of automaticity, the EPN modulation to emotional cues is observed across repeated stimulus presentations of the same materials and occurs in the absence of an active task instruction. Thus, in the absence of interference by concurrent stimulus processing, selective emotional processing appears to be unintentional, effortless, and presumably precedes conscious recognition. Conversely, the EPN is subject to interference by intentional goals held in mind and the processing of immediately preceding emotional cues. Thus, concurrent and successively presented pictures are characterized by distinct neural representations, which may compete for a limited pool of processing resources, attenuating or abolishing selective emotion processing. Taken together, albeit preliminary, results appear to support component features rather than all-ornothing concepts of automaticity (Bargh, 1989). Further research is needed to explore the boundary conditions of the EPN modulation with regard to the various component features of automaticity.

Another interesting issue is to delineate dissociations among the various processing stages reflecting 
the emotional attention capture. In passive viewing contexts, emotional EPN and LPP modulation appear similar in many respects, that is, not subject to habituation and most pronounced for higharousing pleasant and unpleasant materials. However, when paying attention to emotion, boosted processing effects were only observed for the LPP, suggesting that the relationship of emotion and attention changes across time from independent $(\mathrm{EPN})$ to synergistic effects (LPP). Thus, interaction effects of explicit attention and implicit emotion processes vary for distinct processing stages. Future studies are needed to extend these findings including subject populations (e.g., phobia, substance abuse) demonstrating exaggerated attentional orienting to specific stimuli.

\section{Selective attention to emotion: two-stage models of stimulus perception}

It might be informative to consider the ERP findings reviewed above from the broader perspective of two-stage models of stimulus perception. Integrating research from cognitive psychology, the orienting reflex, and associative learning (Öhman, 1979, 1986), a two-stage model was proposed to explicate how emotional, novel, and task-relevant stimuli guide selective attention. The model proposed a first large capacity perceptual scanning stage providing a more or less complete analysis of sensory information. Upon detection of significant stimuli, the perceptual system may emit a call for processing resources in a capacity-limited second stage of stimulus processing acting as gateway to focused attention and conscious recognition. Empirical support for this view is brought out by research with the attentional blink and rapid visual serial presentations. This research determined that pictures can be recognized and comprehended at rapid rates while memory probed immediately afterwards appears quite poor. Potter (Chun and Potter, 1995; Potter, 1999) suggested that stimulus recognition occurs rapidly within the first few hundred milliseconds. However, for conscious stimulus recognition, this fleeting stage of processing needs to be followed by a second stage of consolidation in short-term memory. Two-stage models of stimulus perception may provide a framework to gain more specific hypotheses regarding the functional significance of ERP indices of selective attention. Specifically, the EPN associated with the perceptual encoding of emotional material may reflect the call for resources in the capacity-limited second stage of processing. However, to become consciously represented, stimuli need to have access to the second processing stage, which might be indexed by the LPP component. Furthermore, the elaborate and sustained attentive processing of emotional stimuli is presumably reflected by the sustained positive slow waves. Thus, the call for processing resources triggered after initial stimulus categorization assures that emotional stimuli have priority access to a capacity-limited stage required for working memory consolidation and conscious recognition. Considered from a functional and evolutionary perspective, this priority processing of emotional cues facilitates adaptive behavior, finally promoting survival and reproductive success (Lang et al., 1997; Öhman et al., 2000a).

The various two-stage models of stimulus perception suggest the rapid perceptual categorization of stimuli. Consistent with this view, available data suggest that the differential processing of emotional cues is consequent upon access to semantic meaning. Indirect evidence was provided by the similar latency of emotion discrimination and explicit attention effects obtained in simple feature and higher-order object-based attention tasks (Smid et al., 1999; Potts and Tucker, 2001; Delorme et al., 2004; Codispoti et al., in press ). More direct evidence was provided in a recent study examining explicit attention to emotional cues (Schupp et al., submitted; see above). Findings revealed that explicit attention effects and selective emotion processing appeared with similar latency suggesting that perceptual categorization up to the level of semantic meaning was achieved.

One advantage of considering the ERP findings in the context of two-stage models of stimulus perception is that a common frame is provided for considering the effects of the various active and passive forms of attentional orienting. Specifically, the call for processing resources is thought to reflect short- and long-term memory mechanisms (Öhman et al., 2000a). Emotional stimuli capture 
attention because they include 'tags' on memory representations denoting significant environmental elements in the environment. Active attention effects are considered to reflect the expectancy of certain objects; that is, the temporary activation of long-term memories. In contrast, passive attention effects as observed by the classical orienting responses are thought to reflect the failure to match current stimuli to the content of the short-term memory store. Considering the competition and cooperation studies of the emotion-attention interaction suggests that the call for processing resources triggered by the various forms of attentional control are independent from each other and may compete for processing resources. Furthermore, consistent with the main theme of the present review to consider the emotional guidance of attention in distinct processing stages, interaction patterns changed across processing stages and showed synergistic effects in the second stage associated with stimulus representation in working memory. Clearly, these hypotheses are speculative and await future research. One promising avenue to pursue this view is to complement information regarding the temporal dynamics revealed by ERPs with structural information obtained with fMRI. Overall, reviewing the ERP findings from the perspective of two stage models specifies hypotheses regarding the functional significance of distinct ERP components from a broader theoretical context and suggests multiple avenues to explore the emotion-attention interaction in future research.

\section{Abbreviations}

$\begin{array}{ll}\text { CSD } & \text { current-source-density } \\ \text { EEG } & \text { electroencephalogram } \\ \text { EPN } & \text { early posterior negativity } \\ \text { ERP } & \text { event-related potential } \\ \text { FMRI } & \text { functional magnetic resonance } \\ & \text { imaging } \\ \text { LPP } & \text { late positive potential } \\ \text { L2-MNE } & \text { L2-minimum-norm-estimate } \\ \text { RSVP } & \text { rapid serial visual presentation }\end{array}$

\section{Acknowledgments}

This work was supported by the German Research Foundation (DFG) Grants Schu 1074/7-3 and 1074/10-1. Address reprint requests to Harald T. Schupp at the Department of Psychology, University of Konstanz, Universitätsstr. 10, 78457 Konstanz, Germany.

\section{References}

Amrhein, C., Muhlberger, A., Pauli, P. and Wiedemann, G. (2004) Modulation of event related brain potentials during affective picture processing: a complement to startle reflex and skin conductance response? Int. J. Psychophysiol., 54: 231240.

Anderson, A.K., Christoff, K., Panitz, D., De Rosa, E. and Gabrieli, J.D. (2003) Neural correlates of the automatic processing of threat facial signals. J. Neurosci., 23: 56275633.

Armony, J.L. and Dolan, R.J. (2002) Modulation of spatial attention by fear conditioned stimuli: an event related fMRI study. Neuropsychologia, 40: 817826 .

Bar, M. (2003) A cortical mechanism for triggering top down facilitation in visual object recognition. J. Cogn. Neurosci., 15: 600609.

Barbas, H. (1995) Anatomic basis of cognitive emotional in teractions in the primate prefrontal cortex. Neurosci. Biobehav. Rev., 19: 499510.

Bargh, J.A. (1989) Conditional automaticity: varieties of auto matic influence in social perception and cognition. In: Ule man, J.S. and Bargh, J.A. (Eds.), Unintended Thought. Guilford Press, New York, pp. 351.

Birbaumer, N., Elbert, T., Canavan, A.G. and Rockstroh, B. (1990) Slow potentials of the cerebral cortex and behavior. Physiol. Rev., 70: 141.

Bradley, M.M. (2000) Emotion and motivation. In: Cacioppo, J.T., Tassinary, L.G. and Berntson, G. (Eds.), Handbook of Psychophysiology. Cambridge University Press, New York, pp. 602642 .

Bradley, M.M., Codispoti, M., Cuthbert, B.N. and Lang, P.J. (2001) Emotion and motivation I: defensive and appetitive reactions in picture processing. Emotion, 1: 276298.

Bradley, M.M., Lang, P.J. and Cuthbert, B.N. (1993) Emotion, novelty, and the startle reflex: habituation in humans. Behav. Neurosci., 107: 970980.

Breiter, H.C., Etcoff, N.L., Whalen, P.J., Kennedy, W.A., Ra uch, S.L., Buckner, R.L., et al. (1996) Response and habit uation of the human amygdala during visual processing of facial expression. Neuron, 17: 875887.

Buchel, C. and Dolan, R.J. (2000) Classical fear conditioning in functional neuroimaging. Curr. Opin. Neurobiol., 10: 219223. 
Cacioppo, J.T., Crites Jr., S.L., Berntson, G.G. and Coles, M.G. (1993) If attitudes affect how stimuli are processed should they not affect the event related brain potential. Psy chol. Sci., 4: 108112.

Cacioppo, J.T., Gardner, W.L. and Berntson, G.G. (1999) The affect system has parallel and integrative processing compo nents: form follows function. J. Pers. Soc. Psychol., 76: 839855.

Chun, M.M. and Potter, M.C. (1995) A two stage model for multiple target detection in rapid serial visual presentation. J. Exp. Psychol. Hum. Percept. Perform., 21: 109127.

Codispoti, M., Ferrari, V. and Bradley, M.M. (2006) Repetitive picture processing: autonomic and cortical correlates. Brain Res., 1068: 213220.

Codispoti, M., Ferrari, V., Junghofer, M. \& Schupp, H.T. (in press) The categorization of natural scenes: brain atten tion networks revealed by dense sensor ERPs. Neuroimage.

Compton, R.J. (2003) The interface between emotion and at tention: a review of evidence from psychology and neurosci ence. Behav. Cogn. Neurosci. Rev., 2: 115129.

Cuthbert, B.N., Schupp, H.T., Bradley, M., McManis, M. and Lang, P.J. (1998) Probing affective pictures: attended startle and tone probes. Psychophysiology, 35: 344347.

Cuthbert, B.N., Schupp, H.T., McManis, M.H., Hillman, C., Bradley, M.M. and Lang, P.J. (1995) Cortical slow waves: emotional perception and processing [Abstract]. Psychophys iology, 32: S27.

Cuthbert, B.N., Lang, P.J., Strauss, C., Drobes, D., Patrick, C.J. and Bradley, M.M. (2003) The psychophysiology of anxiety disorder: fear memory imagery. Psychophysiology, 40: 407422.

Cuthbert, B.N., Schupp, H.T., Bradley, M.M., Birbaumer, N. and Lang, P.J. (2000) Brain potentials in affective picture processing: covariation with autonomic arousal and affective report. Biol. Psychol., 52: 95111.

Davis, M. and Whalen, P.J. (2001) The amygdala: vigilance and emotion. Mol. Psychiatry, 6: 1334.

Delorme, A., Rousselet, G.A., Mace, M.J. and Fabre Thorpe, M. (2004) Interaction of top down and bottom up processing in the fast visual analysis of natural scenes. Brain. Res. Cogn. Brain Res., 19: 103113.

Derryberry, D. and Tucker, D.M. (1991) The adaptive base of the neural hierarchy: elementary motivational controls of network function. In: Dienstbier, A. (Ed.), Nebraska Symposium on Motivation. University of Nebraska Press, Lincoln, NE, pp. 289342.

Desimone, R. and Duncan, J. (1995) Neural mechanisms of selective visual attention. Annu. Rev. Neurosci., 18: 193222.

Dickinson, A. and Balleine, B.W. (2002). The role of learning in motivation. In: Gallistel C.R. (Ed.), Steven's Handbook of Experimental Psychology, Vol 3, Learning, Motivation and Emotion, 3rd edn. Wiley, New York, pp. 497533.

Dickinson, A. and Dearing, M.F. (1979) Appetitive aversive interactions and inhibitory processes. In: Dickinson, A. and Boakes, R.A. (Eds.), Mechanisms of Learning and Motivation. Lawrence Erlbaum Associates, Hillsdale, NJ, pp. 203231.
Diedrich, O., Naumann, E., Maier, S.G.B. and Bartussek, D. (1997) A frontal positive slow wave in the ERP associated with emotional slides. J. Psychophysiol., 11: 7184.

Donchin, E. and Coles, M.G. (1988) Is the P300 component a manifestation of context updating? Behav. Brain Sci., 11: 357427.

Donchin, E., Kramer, A.E. and Wickens, C. (1986) Applica tions of brain event related potentials to problems in engi neering psychology. In: Coles, M.G.H., Donchin, E. and Porges, S.W. (Eds.), Psychophysiology: Systems, Processes, and Applications. Guilford Press, New York, pp. 702718.

Ferguson, M.J. and Bargh, J.A. (2003) The constructive nature of automatic evaluation. In: Musch, J. and Klauer, K.C. (Eds.), Psychology of Evaluation: Affective Processes in Cognition and Emotion. Lawrence Erlbaum Associates, Mahwah, NJ, pp. 169188.

Flaisch, T., Junghofer, M., Bradley, M.M., Schupp, H.T. and Lang, P.J. (submitted) Rapid picture processing: affective primes and targets.

Franken, I.H., Hulstijn, K.P., Stam, C.J., Hendriks, V.M. and van den Brink, W. (2004) Two new neurophysiological in dices of cocaine craving: evoked brain potentials and cue modulated startle reflex. J. Psychopharmacol., 18: 544552.

Franken, I.H., Stam, C.J., Hendriks, V.M. and van den Brink, W. (2003) Neurophysiological evidence for abnormal cogni tive processing of drug cues in heroin dependence. Psycho pharmacology, 170: 205212.

Frijda, N.H. (1986) The Emotions. Cambridge University Press, Cambridge.

Ghashghaei, H.T. and Barbas, H. (2002) Pathways for emotion: interactions of prefrontal and anterior temporal pathways in the amygdala of the rhesus monkey. Neuroscience, 115: 12611279.

Globisch, J., Hamm, A.O., Esteves, F. and Ohman, A. (1999) Fear appears fast: temporal course of startle reflex potentiat ion in animal fearful subjects. Psychophysiology, 36: 6675.

Hamalainen, M.S. and Ilmoniemi, R.J. (1994) Interpreting magnetic fields of the brain: minimum norm estimates. Med. Biol. Eng. Comput., 32: 3542.

Hamm, A.O., Cuthbert, B.N., Globisch, J. and Vaitl, D. (1997) Fear and the startle reflex: blink modulation and autonomic response patterns in animal and mutilation fearful subjects. Psychophysiology, 34: 97107.

Hamm, A.O., Schupp, H.T. and Weike, A.I. (2003) Motiva tional organization of emotions: autonomic changes, cortical responses, and reflex modulation. In: Davidson, R.J., Scherer, K. and Goldsmith, H.H. (Eds.), Handbook of Affective Sci ences. Oxford University Press, Oxford, pp. 188211.

Hauk, O., Keil, A., Elbert, T. and Muller, M.M. (2002) Com parison of data transformation procedures to enhance top ographical accuracy in timeseries analysis of the human EEG. J. Neurosci. Methods, 113: 111122.

Hoffman, J.E., Simons, R.F. and Houck, M. (1983) The effects of automatic and controlled processing on the P300. Psy chophysiology, 20: 625632 .

Holmes, A., Vuilleumier, P. and Eimer, M. (2003) The process ing of emotional facial expression is gated by spatial 
attention: evidence from event related brain potentials. Brain. Res. Cogn. Brain Res., 16: 174184.

Johnson Jr., R. (1988) The amplitude of the P300 component of the event related potential: review and synthesis. In: Ackles, P.K., Jennings, J.R. and Coles, M.G.H. (Eds.) Advances in Psychophysiology, Vol. 3. JAI Press, Greenwich, pp. 69138. Johnston, V.S., Miller, D.R. and Burleson, M.H. (1986) Mul tiple $\mathrm{P} 3 \mathrm{~s}$ to emotional stimuli and their theoretical signifi cance. Psychophysiology, 23: 684694.

Johnston, V.S. and Oliver Rodriguez, J.C. (1997) Facial beauty and the late positive component of event related potentials. J. Sex Res., 34: 188198.

Junghofer, M., Bradley, M.M., Elbert, T.R. and Lang, P.J. (2001) Fleeting images: a new look at early emotion discrim ination. Psychophysiology, 38: 175178.

Junghofer, M., Sabatinelli, D., Bradley, M.M., Schupp, H.T., Elbert, T.R. and Lang, P.J. (2006) Fleeting images: rapid affect discrimination in the visual cortex. Neuroreport, 17: 225229.

Junghofer, M., Schupp, H.T., Stark, R. and Vaitl, D. (2005) Neuroimaging of emotion: empirical effects of proportional global signal scaling in fMRI data analysis. Neuroimage, 25: 520526.

Kastner, S. and Ungerleider, L.G. (2000) Mechanisms of visual attention in the human cortex. Annu. Rev. Neurosci., 23: 315341.

Keil, A., Bradley, M.M., Hauk, O., Rockstroh, B., Elbert, T. and Lang, P.J. (2002) Large scale neural correlates of affec tive picture processing. Psychophysiology, 39: 641649.

Keysers, C. and Perrett, D.I. (2002) Visual masking and RSVP reveal neural competition. Trends Cogn. Sci., 6: 120125.

Klauer, K.C. and Musch, J. (2003) Affective priming: findings and theories. In: Musch, J. and Klauer, K.C. (Eds.), The Psychology of Evaluation: Affective Processes in Cognition and Emotion. Erlbaum, Mahwah, NJ, pp. 749.

Konorski, J. (1967) Integrative Activity of the Brain: An Inter disciplinary Approach. University of Chicago Press, Chicago.

Kranczioch, C., Debener, S. and Engel, A.K. (2003) Event related potential correlates of the attentional blink phenom enon. Brain Res. Cogn. Brain Res., 17: 177187.

Lang, P.J., Bradley, M.M. and Cuthbert, B.N. (1990) Emotion, attention, and the startle reflex. Psychol. Rev., 97: 377395.

Lang, P.J. (1995) The emotion probe: studies of motivation and attention. Am. Psychol., 50: 371385.

Lang, P.J., Bradley, M.M. and Cuthbert, B.N. (1997) Moti vated attention: affect, activation, and action. In: Lang, P.J., Simons, R.F. and Balaban, M. (Eds.), Attention and Emo tion: Sensory and Motivational Processes. Erlbaum, Mah wah, NJ, pp. 97135.

Lang, P.J., Bradley, M.M. and Cuthbert, B.N. (2005). Interna tional affective picture system (IAPS): digitized photographs, instruction manual and affective ratings. Technical Report A 6. University of Florida, Gainesville, FL.

Low, A., Lang, P.J. and Bradley, M.M. (2005) What pops out during rapid picture presentation? [Abstract]. Psychophysi ology, 42: S81.

Luck, S.J. and Hillyard, S.A. (2000) The operation of selective attention at multiple stages of processing: evidence from human and monkey electrophysiology. In: Gazzaniga, M.S. (Ed.), The Cognitive Neurosciences (2nd edn). MIT Press, Cambridge.

Luck, S.J., Woodman, G.F. and Vogel, E.K. (2000) Event re lated potential studies of attention. Trends Cogn. Sci., 4: 432440.

Lutzenberger, W., Elbert, T. and Rockstroh, B. (1987) A brief tutorial on the implications of volume conduction for the interpretation of the EEG. J. Psychophysiol., 1: 8190.

Michalowski, J.M., Melzig, C.A., Schupp, H.T. and Hamm, A.O. (2005) Cortical processing of emotional pictures in spi der phobic students [Abstract]. Psychophysiology, 42: S89.

Miltner, W.H., Trippe, R.H., Krieschel, S., Gutberlet, I., He cht, H. and Weiss, T. (2005) Event related brain potentials and affective responses to threat in spider/snake phobic and non phobic subjects. Int. J. Psychophysiol., 57: 4352.

Mogg, K. and Bradley, B.P. (1999) Selective attention and anxiety: a cognitive motivational perspective. In: Dalgleish, T. and Power, M.J. (Eds.), Handbook of Cognition and Emotion. Wiley, Chichester, pp. 145170.

Morris, J.S., Buchel, C. and Dolan, R.J. (2001) Parallel neural responses in amygdala subregions and sensory cortex during implicit fear conditioning. Neuroimage, 13: 10441052.

Nieuwenhuis, S., Aston Jones, G. and Cohen, J.D. (2005) De cision making, the P3, and the locus coeruleus nor epinephrine system. Psychol. Bull., 131: 510532.

Ohman, A. (1979) The orienting response, attention, and learn ing: an information processing perspective. In: Kimmel, H.D., van Olst, E.H. and Orlebek, J.F. (Eds.), The Orient ing Reflex In Humans. Erlbaum, Hillsdale, NJ, pp. 443471.

Ohman, A. (1986) Face the beast and fear the face: animal and social fears as prototypes for evolutionary analyses of emo tion. Psychophysiology, 23: 123145.

Ohman, A., Flykt, A. and Lundqvist, D. (2000a) Unconscious emotion: evolutionary perspectives, psychophysiological data and neuropsychological mechanisms. In: Lane, R.D. and Nadel, L. (Eds.), Cognitive Neuroscience of Emotion. Ox ford University Press, Oxford, pp. 296327.

Ohman, A., Hamm, A. and Hugdahl, K. (2000b) Cognition and the autonomic nervous system: orienting, anticipation, and conditioning. In: Cacioppo, J.T., Tassinary, L.G. and Berns ton, G.G. (Eds.), Handbook of Psychophysiology (2nd edn.). Cambridge University Press, Cambridge, UK, pp. 533575.

Palomba, D., Angrilli, A. and Mini, A. (1997) Visual evoked potentials, heart rate responses and memory to emotional pictorial stimuli. Int. J. Psychophysiol., 27: 5567.

Pessoa, L., Kastner, S. and Ungerleider, L.G. (2002a) Attent ional control of the processing of neutral and emotional stimuli. Brain Res. Cogn. Brain Res., 15: 3145.

Pessoa, L., McKenna, M., Gutierrez, E. and Ungerleider, L.G. (2002b) Neural processing of emotional faces requires atten tion. Proc. Natl. Acad. Sci. USA, 99: 1145811463.

Phan, K.L., Liberzon, I., Welsh, R.C., Britton, J.C. and Taylor, S.F. (2003) Habituation of rostral anterior cingulate cortex to repeated emotionally salient pictures. Neuropsychopharma cology, 28: 13441350.

Picton, T.W. (1992) The P300 wave of the human event related potential. J. Clin. Neurophysiol., 9: 456479. 
Potter, M.C. (1999) Understanding sentences and scenes: the role of conceptual short term memory. In: Coltheart, V. (Ed.), Fleeting Memories. MIT Press, Cambridge, MA, pp. 1346.

Potter, M.C., Staub, A. and O'Connor, D.H. (2002) The time course of competition for attention: attention is initially labile. J. Exp. Psychol. Hum. Percept. Perform., 28: 11491162.

Potts, G.F. and Tucker, D.M. (2001) Frontal evaluation and posterior representation in target detection. Brain Res. Cogn. Brain Res., 11: 147156.

Pourtois, G., Grandjean, D., Sander, D. and Vuilleumier, P. (2004) Electrophysiological correlates of rapid spatial orient ing towards fearful faces. Cereb. Cortex, 14: 619633.

Ritter, W. and Ruchkin, D.S. (1992) A review of event related potential components discovered in the context of studying P3. Ann. NY. Acad. Sci., 658: 132.

Ruchkin, D.S., Johnson Jr., R., Mahaffey, D. and Sutton, S. (1988) Toward a functional categorization of slow waves. Psychophysiology, 25: 339353.

Sabatinelli, D., Bradley, M.M., Fitzsimmons, J.R. and Lang, P.J. (2005) Parallel amygdala and inferotemporal activation reflect emotional intensity and fear relevance. Neuroimage, 24: 12651270.

Schneirla, T. (1959) An evolutionary and developmental theory of biphasic processes underlying approach and withdrawal. In: Jones, M. (Ed.), Nebraska Symposium on Motivation. University of Nebraska Press, Lincoln, pp. 142.

Schupp, H.T., Cuthbert, B.N., Bradley, M.M., Birbaumer, N. and Lang, P.J. (1997) Probe P3 and blinks: two measures of affective startle modulation. Psychophysiology, 34: 16.

Schupp, H.T., Cuthbert, B.N., Bradley, M.M., Cacioppo, J.T., Ito, T. and Lang, P.J. (2000a) Affective picture processing: the late positive potential is modulated by motivational rel evance. Psychophysiology, 37: 257261.

Schupp, H.T., Cuthbert, B.N., Bradley, M.M., Hillman, C.H., Hamm, A.O. and Lang, P.J. (2004a) Brain processes in emo tional perception: motivated attention. Cogn. Emotion, 18: 593611.

Schupp, H.T., Junghofer, M., Weike, A.I. and Hamm, A.O. (2003a) Emotional facilitation of sensory processing in the visual cortex. Psychol. Sci., 14: 713.

Schupp, H.T., Junghofer, M., Weike, A.I. and Hamm, A.O. (2003b) Attention and emotion: an ERP analysis of facili tated emotional stimulus processing. Neuroreport, 14: 11071110.

Schupp, H.T., Junghofer, M., Weike, A.I. and Hamm, A.O. (2004b) The selective processing of briefly presented affective pictures: an ERP analysis. Psychophysiology, 41: 441449.
Schupp, H.T., Ohman, A., Junghofer, M., Weike, A.I., Stock burger, J. and Hamm, A.O. (2004c) The facilitated processing of threatening faces: an ERP analysis. Emotion, 4: 189200.

Schupp, H.T., Stockburger, J., Codispoti, M., Junghofer, M., Weike, A.I. and Hamm, A.O. (2006) Stimulus novelty and emotion perception: the near absence of habituation in the visual cortex. Neuroreport, 17: 365369.

Schupp, H.T., Stockburger, J., Codispoti, M., Junghofer, M., Weike, A.I. and Hamm, A.O. (submitted) Selective visual attention to emotion.

Schupp, H.T., Weike, A.I. and Hamm, A. (2000b) Affect and evaluative context: high density ERP recordings during pic ture processing [Abstract]. Psychophysiology, 37: S88.

Smid, H.G., Jakob, A. and Heinze, H.J. (1999) An event related brain potential study of visual selective attention to conjunc tions of color and shape. Psychophysiology, 36: 264279.

Straube, T., Glauer, M., Dilger, S., Mentzel, H.J. and Miltner, W.H. (2005) Effects of cognitive behavioral therapy on brain activation in specific phobia. Neuroimage, 29: 125135.

Thorpe, S., Fize, D. and Marlot, C. (1996) Speed of processing in the human visual system. Nature, 381: 520522.

Tucker, D.M. (1993) Spatial sampling of head electrical fields: the geodesic sensor net. Electroencephalogr. Clin. $\mathrm{Ne}$ urophysiol., 87: 154163.

Vrana, S.R., Constantine, J.A. and Westman, J.S. (1992) Startle reflex modification as an outcome measure in the treatment of phobia: two case studies. Behav. Assess., 14: 279291.

Vuilleumier, P. (2005) How brains beware: neural mechanisms of emotional attention. Trends Cogn. Sci., 9: 585594.

Vuilleumier, P., Richardson, M.P., Armony, J.L., Driver, J. and Dolan, R.J. (2004) Distant influences of amygdala lesion on visual cortical activation during emotional face processing. Nat. Neurosci., 7: 12711278.

Vuilleumier, P. and Schwartz, S. (2001) Beware and be aware: capture of spatial attention by fear related stimuli in neglect. Neuroreport, 12: 11191122.

Wieser, M.J., Muhlberger, A., Alpers, G.W., Macht, M., Ellg ring, H. and Pauli, P. (2006) Emotion processing in Parkin son's disease: dissociation between early neuronal processing and explicit ratings. Clin. Neurophysiol., 117: 94102.

Wright, C.I., Fischer, H., Whalen, P.J., McInerney, S.C., Shin, L.M. and Rauch, S.L. (2001) Differential prefrontal cortex and amygdala habituation to repeatedly presented emotional stimuli. Neuroreport, 12: 379383.

Yamasaki, H., LaBar, K.S. and McCarthy, G. (2002) Disso ciable prefrontal brain systems for attention and emotion. Proc. Natl. Acad. Sci. USA, 99: 1144711451. 